\title{
CHẤT LƯỢNG SỐNG LIÊN QUAN ĐẾN SỨC KHỎE Ở TRẺ MẮC BASEDOW SỬ DỤNG THANG ĐO PedsQL ${ }^{\text {TM }} 4.0$
}

\section{TÓM TẮT}

Mục tiêu: Đánh giá chất lượng sống (CLS) liên quan đến sức khỏe ở trẻ mắc Basedow. Đối tượng: 80 trẻ mắc Basedow từ 8 đến 18 tuổi đã được chẩn đoán, điều trị và theo dõi điều trị tại bệnh viện Nội tiết Trung ương từ tháng 7/2020 đến tháng 6/2021, được đánh giá CLS liên quan đến sức khỏe bằng thang đo PedsQL ${ }^{T M}$ 4.0. Phương pháp: Nghiên cứu mô tả. Kết quả: Điểm CLS liên quan đến sức khỏe do trẻ mắc Basedow (8-18 tuổi) tự báo cáo trong các lĩnh vực thể chất, cảm xúc, quan hệ xã hội, học tập và CLS tổng quát lần lượt là: $80,16 \pm 11,61 ; 68,63 \pm 10,99 ; 83,94$ $\pm 7,06 ; 73,50 \pm 9,12 ; 77,02 \pm 8,44$. Điêm CLS do bố/me trẻ mắc Basedow báo cáo tương ứng lần lượt là: $79,65 \pm 7,80 ; 71,75 \pm 10,47 ; 83,44 \pm 6,68 ; 75,19$ \pm 6,29; 77,79 \pm 5,94. Điểm CLS do trẻ Basedow báo cáo thấp nhất ở lĩnh vực cảm xúc. Có sự khác biệt về điểm CLS giữa trẻ và bố/me trẻ báo cáo ở lînh vực cảm xúc và học tập, tuy nhiên chưa có sự khác biệt giữa điểm CLS tổng quát do trẻ báo cáo và bố/me trẻ báo cáo. Có sự suy giảm về CLS do trẻ Basedow báo cáo ở nhóm tuổi 13-18 tuổi so với nhóm tuổi 8-12 tuổi ở phân lớn các lĩnh vực. Điểm CLS do trẻ mắc Basedow báo cáo ở cả hai nhóm tuổi thấp hơn đáng kể so với điểm CLS do trẻ khỏe mạnh cung độ tuổi báo cáo, đăc biệt ở lĩnh vực thể chất, cảm xúc, học tập và CLS tổng quát. Kết Iuận: Chất lượng sống liển quan đến sức khỏe ở trẻ mắc Basedow bị suy giảm so với trẻ khỏe manh cùng độ tuổi ở hầu hết các lî̃nh vực, đặc biêt trong lĩnh vực thể chất, cảm xúc và học tập.

Tư khóa: Chất lượng sống, trẻ em, Basedow, PedsQL ${ }^{\mathrm{TM}}$ 4.0.

\section{SUMMARY \\ QUALITY OF LIFE RELATED TO HEALTH OF CHILDREN WITH BASEDOW USING THE SCALE PedsQL ${ }^{\mathrm{TM}}$ 4.0}

Objective: To assess the quality of life related to health of children with Basedow. Subject: A total of 80 children with Basedow from 8 to 18 years old were diagnosed, treated and monitored at the National Hospital of Endocrinology from July 2020 to June 2021, and were assessed the health-related quality of life by the scale PedsQL $L^{T M}$ 4.0. Method: Descriptive study. Results: The health-related quality of life scores of children with Basedow (from 8 to 18 years old) by the child self-reported in the fields of physical, emotional, social, school and general quality of life

${ }^{1}$ Đại hou Y Hà Nọi

²Bệnh viện Nội tiết Trung ương

Chịu trách nhiệm chính: Vũ Thị Huyền

Email: huyen.hmu91@gmail.com

Ngày nhận bài: 13.5.2021

Ngày phản biên khoa học: 29.6.2021

Ngày duyệt bài: 14.7.2021 respectively: $80,16 \pm 11,61 ; 68,63 \pm 10,99 ; 83,94 \pm$ 7,$06 ; 73,50 \pm 9,12 ; 77,02 \pm 8,44$. The quality of life (QoL) scores of children with Basedow by their parent proxy-reported respectively: 79,65 $\pm 7,80 ; 71,75 \pm$ 10,$47 ; 83,44 \pm 6,68 ; 75,19 \pm 6,29 ; 77,79 \pm 5,94$. The QoL scores of children with Basedow reported reported by self-children were the lowest in the emotional domain. There is a difference in the QoL scores between children and their parents in the emotional and school domains, but there is no difference between general QoL scores reported by the children and their parents. There is a decrease in the QoL scores reported by children with Basedow in the 13-18 years old age group compared to the 8-12 years old age group in almost fields. The QoL scores reported by children with Basedow in both age groups were significantly lower than those reported by healthy children of the same age, especially in the physical, emotional, school and general general QoL. Conclusion: The health-related quality of life in children with Basedow is impaired compared to healthy children of the same age in almost fields, especially in the physical, emotional and school domains.

Key words: Quality of life, children, Basedow, PedsQL'TM 4.0.

\section{I. ĐẶT VẤN ĐỀ}

Basedow là bệnh cường chức năng tuyến giáp kết hợp với bướu phì đại lan tỏa do tự kháng thể kích thích trực tiếp thụ thể tiếp nhận TSH (Thyroid Stimulating Hormon) gây tăng sản xuất và giải phóng hormon tuyến giáp trong máu. Basedow là nguyên nhân phố biến nhất gây cường giáp ở trẻ em, tỷ lệ mắc bệnh ở trẻ em là $0,02 \%$, bệnh thường gặp ở trẻ nữ tuổi vị thành niên (11-15 tuổi) [2]. Đây là bệnh lý tự miễn, có khuynh hướng mạn tính và hay tái phát. Trẻ mắc Basedow thường hạn chế khả năng học tập, vui chơi, sinh hoạt so với các trẻ khỏe mạnh do các triệu chứng của bênh và tác dụng không mong muốn của thuốc điều trị. Hiện nay, trên thế giới đánh giá CLS đối với các bệnh lý mạn tính là một trong những lĩnh vực đang được quan tâm, trong đó có CLS của trẻ Basedow. Trong các công cụ nghiên cứu CLS ở trẻ em, thang đo Pediatric Quality of Life (PedsQL ${ }^{T M} 4.0$ ) là công cụ đánh giá đa lĩnh vực đã được xác định tính hiệu quả và độ tin cậy ở trẻ khỏe mạnh và trẻ mắc các bệnh lý mạn tính tại nhiều quốc gia trên thế giới. Tại Việt Nam, chưa có nghiên cứu nào tìm hiểu vể chẩt lượng sống của trẻ mắc Basedow. Việc đánh giá CLS của trẻ Basedow là cơ sở khoa học giúp đánh giá một cách toàn diện hơn về tình 
trạng sức khỏe của bệnh nhân, từ đó đưa ra các biện pháp can thiệp, điều trị phù hợp đối với bệnh nhân. Nghiên cứu này được tiến hành với mục tiêu: Đánh giá chất lượng sống liên quan đển sức khỏe ở trẻ mắc Basedow bằng thang điểm PedsQL ${ }^{T M}$ 4.0.

\section{II. ĐỐI TƯỢNG VÀ PHƯƠNG PHÁP NGHIÊN CỨU}

2.1. Đối tượng nghiên cứu: 80 bệnh nhân Basedow từ 8 đến 18 tuổi được chẩn đoán và theo dõi tại Bệnh viện Nội tiết Trung ương từ tháng $7 / 2020$ đến tháng $6 / 2021$, có thời gian điều trị bệnh $\geq 3$ tháng.

- Tiêu chuân lựa chọn:

+ Đối tượng nghiên cứu được chẩn đoán xác định Basedow dựa vào các triệu chứng:

- Lâm sàng: biểu hiện nhiễm độc giáp: rối loạn tâm thần, rối loạn thần kinh thực vật, tăng chuyển hóa, bướu cổ, nhịp tim nhanh, lồi mắt...

- Cận lâm sàng: TSH $<0,1 \mu \mathrm{UI} / \mathrm{mL}, \mathrm{FT} 4>25$ $\mathrm{pmol} / \mathrm{L}$ và/hoặc T3 > $3 \mathrm{nmol} / \mathrm{L}, \mathrm{TRAb}>1,58 \mathrm{UI} / \mathrm{L}$.

+ Trẻ và bố/mẹ nói, hiểu được tiếng Kinh.

- Tiêu chuẩn loai trừ:

+ Trẻ có suy giảm chức năng nhận thức vận động, rối loạn cảm xúc hành vi hoặc không có khả năng giao tiếp (câm, điếc); trẻ mắc các bệnh lý mạn tính kèm theo.

+ Bố/mẹ của trẻ mắc bệnh lý tâm thần và thần kinh hoặc không có khả năng giao tiếp.

\subsection{Phương pháp nghiên cứu}

\subsection{Chất lượng sống của trẻ mắc Basedow}

Bảng 3.2. Điêm CLS ở trẻ mắc Basedow ở các lính vực do trẻ và bố/me trẻ báo cáo (818 tuối, $n=80$ )

\begin{tabular}{|c|c|c|c|}
\hline Lĩnh vực & $\begin{array}{c}\text { Trẻ báo cáo } \\
\text { TB } \pm \text { SD (điểm) }\end{array}$ & $\begin{array}{c}\text { Bố/mẹ báo cáo } \\
\text { TB } \pm \text { SD (điểm) }\end{array}$ & p \\
\hline Thế chất & $80,16 \pm 11,61$ & $79,65 \pm 7,80$ & $>0,05$ \\
\hline Cảm xúc & $68,63 \pm 10,99$ & $71,75 \pm 10,47$ & $<0,05$ \\
\hline Quan hệ xã hội & $83,94 \pm 7,06$ & $83,44 \pm 6,68$ & $>0,05$ \\
\hline Hộ tập & $73,50 \pm 9,12$ & $75,19 \pm 6,29$ & $<0,05$ \\
\hline CLS tống quát & $77,02 \pm 8,44$ & $77,79 \pm 5,94$ & $>0,05$ \\
\hline
\end{tabular}

Nhận xét: Điếm CLS do trẻ báo cáo ở lĩnh vực cảm xúc, học tập thấp hơn so với bố/mẹ báo cáo, tuy nhiên sự khác biệt không có ý nghĩa thống kể ở CLS tổng quát.

Bảng 3.3. Điểm CLS theo nhóm tuổi do trẻ báo cáo

\begin{tabular}{|c|c|c|c|}
\hline Lĩnh vực & $\begin{array}{c}\text { Trẻ 8-12 tuối } \\
(\mathbf{n = 2 4 )} \\
\text { TB } \pm \text { SD (điểm) }\end{array}$ & $\begin{array}{c}\text { Trẻ 13-18 tuối } \\
\text { (n=56) } \\
\text { TB } \pm \text { SD (điểm) }\end{array}$ & p \\
\hline Thể chất & $85,81 \pm 7,65$ & $77,73 \pm 12,21$ & $<0,05$ \\
\hline Cảm xúc & $74,58 \pm 10,62$ & $66,07 \pm 10,21$ & $<0,05$ \\
\hline Quan hệ xã hội & $86,04 \pm 6,91$ & $83,04 \pm 6,99$ & $>0,05$ \\
\hline Học tập & $77,08 \pm 6,58$ & $71,96 \pm 9,66$ & $<0,05$ \\
\hline CLS tống quát & $81,52 \pm 5,97$ & $75,10 \pm 8,65$ & $<0,05$ \\
\hline
\end{tabular}

Nhận xét: Điểm CLS do trẻ báo cáo ở nhóm tuổi 13-18 tuổi thấp hơn so với nhóm tuổi 8-12 tuổi ở phần lớn các lĩnh vực, đặc biệt là lĩnh vực thể chất, cảm xúc, học tập và CLS tổng quát, sự khác biệt có ý nghĩa thống kê với $p<0,05$.
- Thiết kế nghiên cứu: mô tả

- Công cụ đánh giá: Thang điểm CLS trẻ em (Pediatric Quality of Life - PedsQL $L^{\mathrm{TM}}$ 4.0) của California [3]

- Chỉ số nghiên cứu: Điểm CLS trên 4 lĩnh vực: thể chất, cảm xúc, quan hệ xã hội (QHXH), và điểm CLS tổng quát. So sánh điểm quần thể tham khảo của Nguyễn Thị Thanh Mai (2017) [1].

phần mềm thống kê SPSS 25.0 tính giá trị trung bình, độ lệch chuẩn, kiểm định T-Test.

\section{KẾT QUẢ NGHIÊN CứU}

3.1. Đặc điểm của đối tượng nghiên cứu. tử 8 đến 18 tuổi, tuổi trung vị là 14,5 tuổi, nhỏ 政 8 tuôi và lớn nhất là 18 tuối.

nghiên cứu

Nhân xét: Đa số trẻ thuộc nhóm tuối từ 1318 tuổi chiếm tỷ lệ $70 \%$. Phần lớn trẻ là nữ giới, tỷ lệ nữ: nam là 5,67:1.

\begin{tabular}{|c|c|c|c|}
\hline $\begin{array}{r}\text { Giới } \\
\text { Lứa tuối }\end{array}$ & $\begin{array}{c}\text { Nam } \\
\mathbf{n ( \% )}\end{array}$ & $\begin{array}{c}\text { Nữ } \\
\mathbf{n}(\%)\end{array}$ & $\begin{array}{c}\text { Tống } \\
\mathbf{n}(\%)\end{array}$ \\
\hline $8-12$ tuối & $3(3,8)$ & $21(26,2)$ & $24(30)$ \\
\hline $13-18$ tuối & $9(11,3)$ & $47(58,7)$ & $56(70)$ \\
\hline Tống & $\mathbf{1 2 ( 1 5 )}$ & $\mathbf{6 8 ( 8 5 )}$ & $\mathbf{8 0 ( 1 0 0 )}$ \\
\hline
\end{tabular}


Bảng 3.4. Điểm CLS ở trẻ mắc Basedow so với trẻ khỏe mạnh

\begin{tabular}{|c|c|c|c|c|c|c|}
\hline \multirow[b]{2}{*}{ Lĩnh vực } & \multicolumn{3}{|c|}{ Trẻ báo cáo (8-12 tuối) $(X \pm S D)$} & \multicolumn{3}{|c|}{ Trẻ báo cáo (13-18 tuối) $(X \pm S D)$} \\
\hline & $\begin{array}{c}\text { Trẻ Basedow } \\
n=24\end{array}$ & $\begin{array}{l}\text { Trẻ khỏe manh* } \\
n=433\end{array}$ & $\mathrm{p}$ & $\begin{array}{c}\text { Trẻ Basedow } \\
n=56\end{array}$ & $\begin{array}{c}\text { Trẻ khỏe manh* } \\
n=396\end{array}$ & $\mathrm{P}$ \\
\hline Thể chất & $85,81 \pm 7,65$ & $92,1 \pm 9,33$ & $<0,05$ & $77,73 \pm 12,21$ & $83,7 \pm 15,08$ & $<0,05$ \\
\hline Cảm xúc & $74,58 \pm 10,62$ & $85,1 \pm 15,63$ & $<0,001$ & $66,07 \pm 10,21$ & $69,9 \pm 18,42$ & $<0,05$ \\
\hline QHXH & $86,04 \pm 6,91$ & $91,2 \pm 12,59$ & $<0,05$ & $83,04 \pm 6,99$ & $84,8 \pm 14,84$ & $>0,05$ \\
\hline Học tập & $77,08 \pm 6,58$ & $91,2 \pm 10,57$ & $<0,001$ & $71,96 \pm 9,66$ & $76,2 \pm 15,89$ & $<0,05$ \\
\hline $\begin{array}{l}\text { CLS tống } \\
\text { quát }\end{array}$ & $2 \pm 5,99$ & $90,2 \pm 9,49$ & $<0,001$ & $75,10 \pm 8,65$ & $79,1 \pm 12,61$ & $<0,05$ \\
\hline
\end{tabular}

Nhận xét: Ở nhóm trẻ từ 8-12 tuối, điểm CLS do trẻ báo cáo thấp hơn trẻ khỏe mạnh ở tất cả các lĩnh vực. Ở nhóm trẻ từ 13-18 tuổi, điểm CLS do trẻ báo cáo thấp hơn trẻ khỏe mạnh ở các lĩnh vực thể chất, cảm xúc, học tập và CLS tổng quát.

\section{BÀN LUẬN}

Thang điểm CLS PedsQL ${ }^{T M} 4.0$ đã được Varni và cộng sự sử dụng rộng rãi trong các nghiên cứu, thực hành lâm sàng và chăm sóc sức khỏe trẻ em [3]. Nghiên cứu sử dụng thang PedsQL ${ }^{\mathrm{TM}}$ 4.0 để đánh giá CLS ở 80 bệnh nhi mắc Basedow có độ tuổi từ 8 đến 18 tuổi, được theo dõi và điều trị tại Bệnh viện Nội tiết Trung ương, trong đó đa số trẻ thuộc nhóm tuổi từ 13-18 tuổi chiếm tỷ lệ $70 \%$ và phần lớn trẻ là nữ giới, tỷ lệ nữ: nam là 5,67:1 (bảng 3.1). Đánh giá điểm CLS trên các lĩnh vực thể chất, cảm xúc, quan hệ xã hội, học tập và CLS tổng quát do trẻ và bố/mẹ trẻ đánh giá.

Kết quả nghiên cứu cho thấy, điểm CLS tổng quát ở trẻ mắc Basedow có độ tuổi từ 8-18 tuổi do trẻ báo cáo đạt 77,02 $\pm 8,44$ thấp hơn so với nghiên cứu của Lane và cộng sự tại Anh (2021) với 79,3 $\pm 19,5$ [4]. Sự khác biệt về điểm CLS tổng quát ở trẻ Basedow trong nghiên cứu này so với nghiên cứu của Lane có thể do sự khác biệt về cỡ mẫu nghiên cứu (Lane và cộng sự nghiên cứu 15 bệnh nhân Basedow từ 8-18 tuổi); sự khác biệt về văn hóa cũng như trình độ phát triển kinh tế - xã hội và sự tiến bộ của y học giữa hai quốc gia là nguyên nhân dẫn đến điểm CLS của trẻ Basedow ở Việt Nam thấp hơn so với nghiên cứu tại Anh. Điểm CLS ở trẻ Basedow do trẻ báo cáo và bô/me trẻ báo cáo đều thấp nhất trong lĩnh vực cảm xúc với điểm CLS tương ứng lân lượt là: $68,63 \pm 10,99$ và $71,75 \pm 10,47$ điểm (bảng 3.2). Điều này cho thấy, trẻ mắc Basedow có sự suy giảm nghiêm trọng $\mathrm{CLS}$, đặc biệt ở lĩnh vực cảm xúc, được đánh giá bởi trẻ cũng như bố/me trẻ. Nguyển nhân có thể do những tác động tiêu cực của tình trạng cường giáp gây nên những thay đổi về cảm xúc và tâm lý của trẻ mắc Basedow. Khi so sánh điểm CLS ở trẻ Basedow giữa trẻ và bố/me trẻ báo cáo nghiên cứu cũng cho thấy có sự khác biệt giữa báo cáo của trẻ và của bố/mẹ trẻ trong các lĩnh vực cảm xúc và học tập. Điểm CLS do trẻ báo cáo thấp hơn điểm CLS do bố/mẹ báo cáo trong lĩnh vực cảm xúc và học tập, tuy nhiên, chưa có sự khác biệt rõ rệt trong điểm CLS tổng quát giữa trẻ và bố/mẹ trẻ Basedow báo cáo (bảng 3.2). Cảm xúc là lĩnh vực được báo cáo dựa trên cảm nhận của bản thân trẻ nển có thể có sự khác biệt với đánh giá của bố/mẹ trẻ.

Khi đánh giá CLS ở trẻ mắc Basedow theo nhóm tuổi, nghiên cứu cho thấy trẻ Basedow thuộc nhóm từ 13-18 tuổi có điểm CLS thấp hơn so với nhóm từ 8-12 tuổi ở phần lớn các lĩnh vực, đặc biệt là lĩnh vực thể chất, cảm xúc, học tập và CLS tổng quát, sự khác biệt có ý nghĩa thống kê với $p<0,05$ (bảng 3.3). Kểt quả này cũng tương tự như nghiên cứu của Lane và cộng sự tại Anh [4] và Riguetto (2018) [5]. Điều này có thể do tuổi vị thành niên là nhóm tuổi có nhiều biến động về thể chất và tâm lý, trẻ dễ bị tổn thương, không ổn định do bệnh hoặc do những biến đồi bình thường trong lứa tuổi này. ở lứa tuổi này, trẻ cũng phát sinh nhiều vấn đề về mối quan hệ giới tính, mối quan hệ với gia đình, bạn bè, thầy cô giáo, cùng với những áp lực với chương trình học tập khiến cho trẻ lo lắng, căng thẳng đã tác động tiêu cực đến CLS của trẻ.

Trẻ mắc Basedow có sự suy giảm nghiêm trọng CLS ở phần lớn các lĩnh vực khi so sánh với trẻ khỏe mạnh cùng độ tuổi trong nghiên cứu của Nguyễn Thị Thanh Mai và cộng sự [1]. Ở nhóm tuổi 8-12 tuổi, điểm CLS do trẻ Basedow báo cáo thấp hơn nhiều so với trẻ khỏe mạnh ở tất cả các lĩnh vực. Ở nhóm tuổi 13-18 tuổi, điểm CLS do trẻ Basedow báo cáo thấp hơn đáng kể so với trẻ khỏe mạnh ở các lĩnh vực thể chất, cảm xúc, học tập và CLS tổng quát (bảng 3.4). Basedow là bệnh lý cường chức năng tuyến giáp, CLS ở trẻ Basedow có thể suy giảm hơn so với trẻ khỏe mạnh do những ảnh hưởng của bệnh hoặc của quá trình điều trị bệnh. Trẻ mắc Basedow thường có các biểu hiệu của tình trạng 
nhiễm độc giáp, có những thay đổi về ngoại hình, tâm lý, ảnh hưởng đến thể chất, cảm xúc, khả năng học tập cũng như mối quan hệ với bạn bè và xã hội. Mặt khác, Basedow là một bệnh lý tự miễn, có khuynh hướng mạn tính và hay tái phát, trẻ Basedow phải uống thuốc thường xuyên và tái khám định kỳ gây ảnh hưởng nhiều đến CLS của trẻ, khiến điểm CLS của trẻ Basedow thấp hơn nhiều so với trẻ khỏe mạnh.

\section{KẾT LUÂ̂N}

Điểm chất lượng sống do trẻ mắc Basedow báo cáo thấp nhất ở lĩnh vực cảm xúc và có sự khác biệt giữa điểm CLS do trẻ và bố/me trẻ báo cáo trong lĩnh vực cảm xúc và học tập. Điểm CLS của trẻ mắc Basedow báo cáo ở nhóm tuổi 8-12 tuổi cao hơn nhóm tuổi 13-18 tuổi. Chất lượng sống liên quan đến sức khỏe ở trẻ mắc Basedow bị suy giảm so với trẻ khỏe mạnh cùng độ tuổi ở phần lớn các lĩnh vực, đặc biệt trong lính vực thể chất, cảm xúc, học tập và CLS tổng quát.
TÀI LIẸU THAM KHẢO

1. Nguyễn Thị Thanh Mai, Trân Thị Nết, Vũ Thương Huyên (2017). Khảo sát chất lượng cuộc sông liên quan sức khỏe ở trẻ em khỏe mạnh bằng thang PedsQL TM4.0 generic core scale, phiên bản Việt Nam. Tạp chí Y học Thực hành: 1045(6), 181-183.

2. Minamitani $K$, Sato $H$, Ohye $H$, et al (2017). Guidelines for the treatment of childhood-onset Graves' disease in Japan. Clinical Pediatric Endocrinology, 26(2): 29-62.

3. Varni J.W, Seid M, Kurtin P.S (2001). PedsQL ${ }^{T M}$ 4.0: reliability and validity of the Pediatric Quality of Life Inventory ${ }^{\mathrm{TM}}$ version 4.0 generic core scales in healthy and patient populations. Medical Care, 39(8): 800-812.

4. Lane L.C, Rankin J., Cheetham T. (2021). A survey of the young person's experience of Graves' disease and its management. Clinical Endocrinology, 94(2): 330-340.

5. Riguetto C.M, Neto A.M, Tambascia M.A et al (2018). The relationship between quality of life, cognition, and thyroid status in Graves' disease. Endocrine, 63(1): 87-93.

\section{ĐÁNH GIÁ THỰC TRANG SỬ DUUNG THUỐC TRÊN BÊNHH NHÂN NGOẠI TRÚ CAO TUỔI BẰNG CÔNG CU STOPP TẠI BỆNH VIỆN TRƯỜNG ĐẠI HỌC Y KHOA VINH}

\section{TÓM TÁ́T}

Mục tiêu: Đánh giá thực trạng đơn thuốc ngoại trú trển bệnh nhân cao tuổi bằng công cu STOPP và khảo sát một số yếu tố liên quan đến chỉ số PIM tại Bênh viên Trường Đai họ $Y$ khoa Vinh. Phương pháp nghiên cứu: Nighiển cứu tiến cứu mô tả cắt ngang, tài liệu nghiên cứu là đơn thuốc, bệnh án ngoại trú của bệnh nhân từ 60 tuổi trở lên tại khoa khám Bênh viên Trường Đai hoc $\mathrm{Y}$ khoa Vinh. Kết quả: Tỷ lệ gặp thuốc có khả năng không thích hợp theo STOPP 2014 trên đơn thuốc ngoai trú trong nghiên cứu là 18,35\%, trong đó ghi nhận được 21 loại PIM, hay gặp nhất là Aspirin ở bệnh nhân có tiền sử loét dạ dày tá tràng không dùng kèm PPI (20,34\%), các sulphonylurea có thời gian tác dụng dài như glibenclamid, glimepirid (13,65\%), PPI điều trị viêm loét dạ dày tá tràng không biến chứng hoặc viêm trợt thực quản khi dùng liều đầy đủ $>8$ tuần $(11,86 \%)$. Các yếu tố làm tăng khả năng gặp PIM theo STOPP 2014 gồm đa dược học OR=2,308 (CI95\%=1,130-

${ }^{1}$ Đại học Y khoa Vinh

Chịu trách nhiệm chính: Nguyễn Văn Tuấn

Email: tuanminh1975@gmail.com

Ngày nhận bài: 17.5.2021

Ngày phản biên khoa hoc: 30.6.2021

Ngày duyệt bài: 16.7.2021

\section{Nguyễn Văn Tuấn ${ }^{1}$, Trần Thị Anh Tho ${ }^{1}$}

$4,711, p=0,022)$, bệnh hệ tiêu hóa $O R=2,694$ $(\mathrm{CI} 95 \%=1,353-5,364, \mathrm{p}=0,005)$ và bệnh hệ tuần hoàn $\mathrm{OR}=2,828 \quad(\mathrm{CI} 95 \%=1,287-6,215, \mathrm{p}=0,010)$. Trong đó bệnh tim mạch là yếu tố có ảnh hưởng mạnh nhất đến khả năng gặp PIM theo STOPP 2014, nhóm bệnh nhân có bệnh tim mạch có nguy cơ gặp PIM cao gấp 2,8 lần so với nhóm không có bệnh tim mạch. Kết luận: Nghiên cứu cho thấy tỷ lệ kê đơn thuốc có khả năng không thích hợp (PIM) là 18,35\%. Hạn chế kê nhiều thuốc trên bệnh nhân cao tuối, đặc biệt từ 5 thuốc trở lên do tăng khả năng gặp PIM. Bệnh nhân mắc bệnh tim mạch hoặc hệ tiêu hóa tăng khả năng găp PIM.

Tư khóa: Người cao tuổi, STOPP, PIM

\section{SUMMARY}

ASSESSING THE STATUS OF DRUG USE IN ELDERLY OUTPATIENTS USING THE STOPP TOOL AT VINH MEDICAL UNIVERSITY HOSPITAL

Objectives: To assess the status of outpatient prescriptions in elderly patients using the STOPP tool and to investigate some factors related to the PIM index at Vinh Medical University Hospital. Methods: A cross-sectional prospective study, the research materials are prescriptions, outpatient medical records of patients with aged 60 years and older at the medical examination department of Vinh Medical University Hospital. Results: The rate of encountering 